\title{
Aplasia cutis-myopia syndrome
}

INSERM

\section{Source}

INSERM. (1999). Orphanet: an online rare disease and orphan drug data base. Aplasia cutis-myopia syndrome. ORPHA:1117

Aplasia cutis-myopia syndrome is characterised by the association of aplasia cutis congenita with high myopia, cong enital nystag mus and cone-rod dysfunction. It has been described in two siblings (brother and sister). Transmission is autosomal dominant. 